\title{
In Silico Studies on Acetylcholine Receptor Subunit Alpha-L1 for Proposal of Novel Insecticides against Aphis craccivora ${ }^{\dagger}$
}

\author{
Ana Borota *, Luminita Crisan, Alina Bora and Simona Funar-Timofei * \\ Coriolan Dragulescu Institute of Chemistry Timisoara, 24 Mihai Viteazul Av., 300223 Timisoara, Romania; \\ lumi_crisan@acad-icht.tm.edu.ro (L.C.); alina.bora@gmail.com (A.B.) \\ * Correspondence: ana_borota@acad-icht.tm.edu.ro (A.B.); timofei@acad-icht.tm.edu.ro (S.F.T.) \\ $\dagger$ Presented at the 24th International Electronic Conference on Synthetic Organic Chemistry, \\ 15 November-15 December 2020; Available online: https://ecsoc-24.sciforum.net/.
}

Citation: Borota, A.; Crisan, L.; Bora, A.; Funar-Timofei, S. In Silico Studies on Acetylcholine Receptor Subunit Alpha-L1 for Proposal of Novel Insecticides against Aphis craccivora. Proceedings 2021, 3, 8. https://doi.org/ 10.3390/ecsoc-24-08366

Academic Editors: Julio A. Seijas and M. Pilar Vázquez-Tato

Published: 14 November 2020

Publisher's Note: MDPI stays neutral with regard to jurisdictional claims in published maps and institutional affiliations.

Copyright: $\odot 2020$ by the authors. Licensee MDPI, Basel, Switzerland. This article is an open access article distributed under the terms and conditions of the Creative Commons Attribution (CC BY) license (http://creativecommons.org/licenses/by/4.0/).

\begin{abstract}
Aphis craccivora is an aphid which damages many species of plants and is also a vector for numerous plant viruses. Since neonicotinoids are a well-known class of effective insecticides with less toxicity against mammals and other vertebrates, a small dataset of compounds retrieved from the literature based on similarity to highly active neonicotinoids was used. Thus, homology modeling was involved in the building of the 3D structure of the acetylcholine receptor subunit alpha-L1 of Aphis craccivora. The homology model was involved in virtual screening experiments using the FRED docking tool of the OpenEye software. The aforementioned dataset was used to explore the intermolecular ligand-target interaction patterns for a rational design of desired and relatively safe insecticides.
\end{abstract}

Keywords: homology model; docking; neonicotinoids; aphid

\section{Introduction}

Aphis craccivora (A. craccivora) is known as one of the most common aphids in the tropics [1] nowadays and has an extended distribution worldwide. This aphid is an important pest, especially in groundnuts, cowpeas, and numerous other leguminous crops. Being considered the most harmful insect of groundnut throughout Africa [2], A. craccivora causes direct feeding and indirect damage, and is a vector for numerous plant viruses [3]. Resistance to organophosphate, nicotine, pyrethroids, and organochlorine insecticides has been observed in A. craccivora populations on various plants in India [4]. Therefore, finding new potential pesticides to prevent the resistance issue is a legitimate goal. After pyrethroid chemicals, neonicotinoids represent a major advance in terms of insecticides [5]. They are a well-known class of effective pesticides with less toxicity against mammals and other vertebrates [6].

In this study, for a better understanding of the mechanism of action of neonicotinoid and neonicotinoid-like compounds, we conducted an in silico experiment consisting of homology modeling and molecular docking procedures. The 3D structure of the neonicotinoid target is experimentally unavailable, therefore the homology model of the acetylcholine receptor subunit alpha-L1 of $A$. craccivora was first built. Further, a small dataset of 648 compounds retrieved from the literature based on the similarity to highly potent neoticotinoids was docked in the binding site of the homology model. Knowing that neonicotinoids are pesticides involved in the decline of bees [7], the dataset was preliminarily investigated using the BeeTox tool [8] to predict the bee toxicity of these compounds and they were found to be safe. The aforementioned dataset was used to explore the intermolecular ligand-target interaction patterns for a rational design of desired insecticides. The docking results were analyzed by inspecting the key ligand-target interactions and the ranking of the docking scores. 


\section{Methods}

The homology model for the acetylcholine receptor subunit alpha-L1 of A. craccivora (GenBank ID: KAF0770983.1) was realized using the Swiss Model server [9,10]. In the first instance, the KAF0770983.1 sequence was used to find the most appropriate template. As the complex of human alpha3beta4 nicotinic acetylcholine receptor with nicotine (6PV7 PDB ID) was identified by the Swiss Model software, taking into account the best coverage score, it was further used as a template in the homology modeling process. It was observed that the binding site of the 6PV7 protein is located between the chains of two monomer units. Thus, the sequence alignment of the A and B chains of the 6PV7 receptor and the KAF0770983.1 sequence of the target was achieved using the Blast server [11]. The alignment obtained for each chain was then submitted to the "alignment of the target sequence and template structure(s)" module of the Swiss Model server. Finally, the raw homology model consisting of two chains (A and B) was obtained and a process of refining and optimizing was undertaken using the Maestro software from the Schrodinger suite (https://www.schrodinger.com/) and the Deep View Swiss-Pdb Viewer version 4.1.0 program [12]. The loops that were observed as having problems were remodeled and the steric clashes between the side chains of the amino acid residues were removed by choosing the right rotamers for them. To attest the stereochemical quality of the homology model, the PROCHECK server was involved [13].

A dataset of 648 compounds retrieved from the literature [14-34] was used in the virtual screening experiments based on their similarity to highly active neonicotinoids. In advance, the compounds were prepared for docking studies using the OMEGA software $[35,36]$ using the $94 \mathrm{~s}$ Merck molecular force field (MMFF) option for the minimization of the generated conformers.

The homology structure was prepared with Make Receptor 3.5.0.4 and then the FRED 3.5.0.4 tool (Open Eye Scientific Software) [37-39] was utilized for molecular docking. Every conformer was docked into the protein-binding site with the aid of the FRED program, which uses an exhaustive rotation-translation search algorithm.

\section{Results and Discussion}

The sequence alignment between the target and template resulting from the Blast server and further used for the building of the quaternary homology model is presented in Figure 1. The visualization of the alignment was done using BIOVIA software (Dassault Systèmes, Vélizy-Villacoublay CEDEX-France) [40].

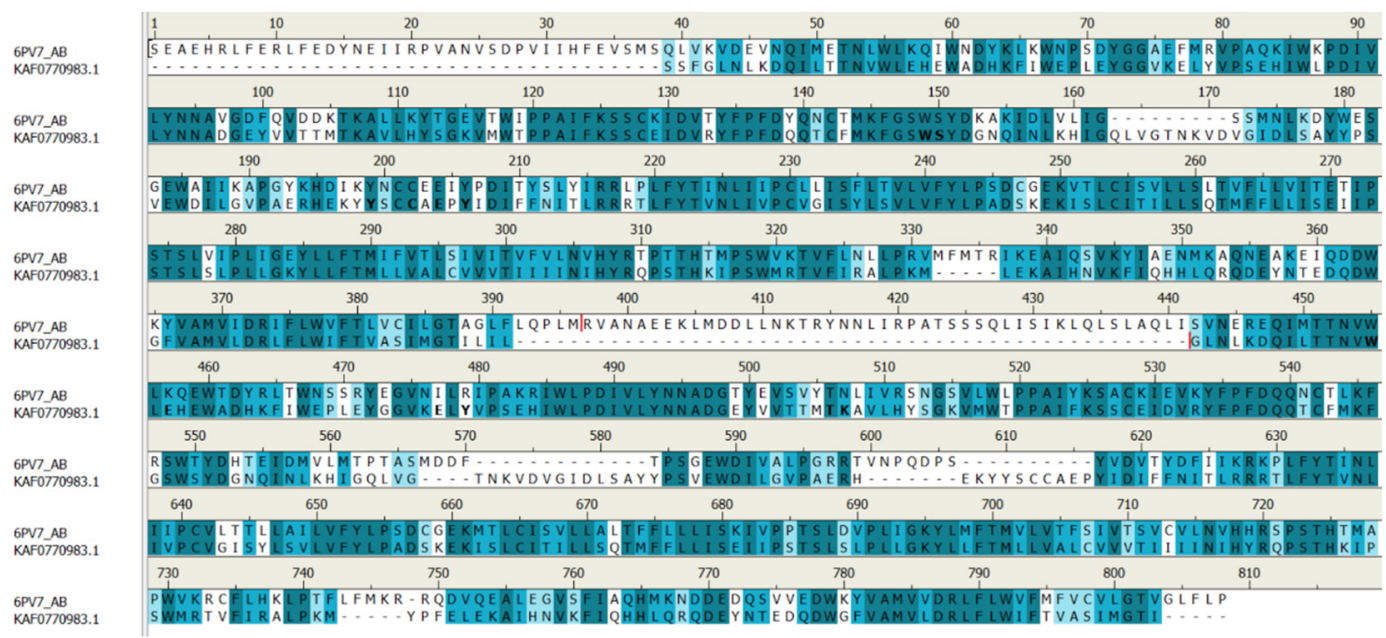

Figure 1. The sequence alignment was achieved between the query (KAF0770983.1-GenBank ID, acetylcholine receptor subunit alpha-L1 (Aphis craccivora)) and the template (6PV7|Chains A, B I - PDB ID, Fusion protein of Neuronal acetylcholine receptor subunit alpha-3 and Soluble cytochrome b562।Homo sapiens). The similarity character of the alignment is highlighted by increasing the color intensity (white-dissimilar amino acids, dark blue-identical amino acids). The identified binding site amino acid residues are depicted in bold. 
The raw homology model was evaluated using the PROCHECK server [13] to check its stereochemical quality through a series of plots for the analysis of its overall and residue-by-residue geometry. The Ramachandran map is an important tool for the validation of a good protein's geometry. A good quality protein structure would be expected to have over $90 \%$ residues in the most favored regions. The refined homology model has 564 residues $(90.4 \%)$ in the most favored regions [A,B,L]; 59 residues $(9.5 \%)$ in the additional allowed regions $[a, b, 1, p] ; 1(0.2 \%)$ residue in the generously allowed regions $[\sim a, \sim b, \sim 1, \sim p]$; and 0 residues in disallowed regions (Figure 2 ). The main and side chain parameters were also analyzed and were observed to be within the allowed mean or even better. After iterative steps of refining and evaluation, the final model was validated, as shown in the plots in Figures 2 and 3.

The dimeric structure of the homology model and the identified binding site located between its two monomer units is presented in Figure 4.

The docking of the selected dataset of 648 compounds led to their ranking. Thus, considering the best FRED Chemgauss4 score values, the top four compounds were chosen for further analyses (Table 1).

Table 1. Top four compounds resulting from the FRED docking ranking.<smiles>O=C1c2cccnc2C(=O)N1Cc1ccccc1</smiles><smiles>COc1ccc(N)cc1S(=O)(=O)Nc1ccccc1</smiles><smiles>COc1ccc(N)cc1S(=O)(=O)Nc1ccc(Cl)cc1</smiles><smiles>O=C1C=C(N(Cc2ccc(Cl)nc2)CC(F)F)CO1</smiles> 


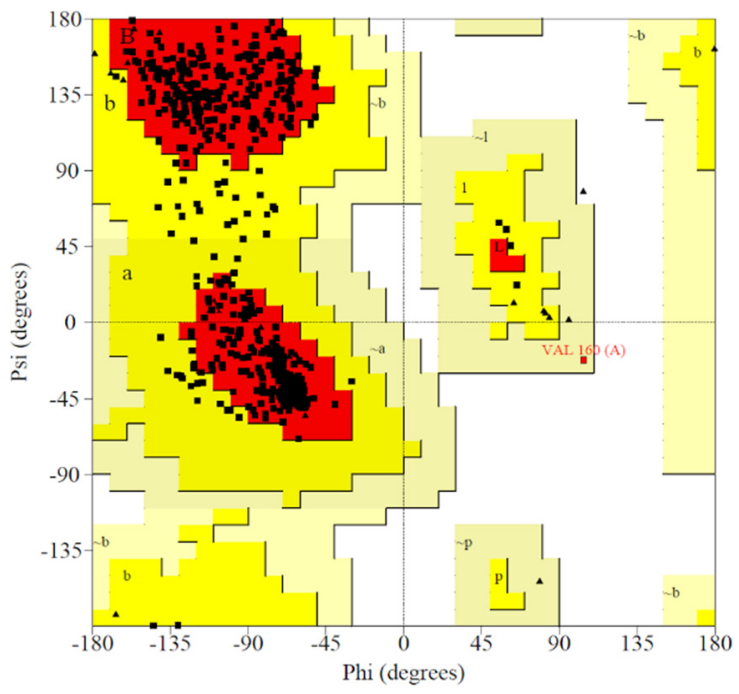

Figure 2. The Ramachandran plot of the refined homology model with $90.4 \%$ residues in mostfavored regions $[\mathrm{A}, \mathrm{B}, \mathrm{L}]$.
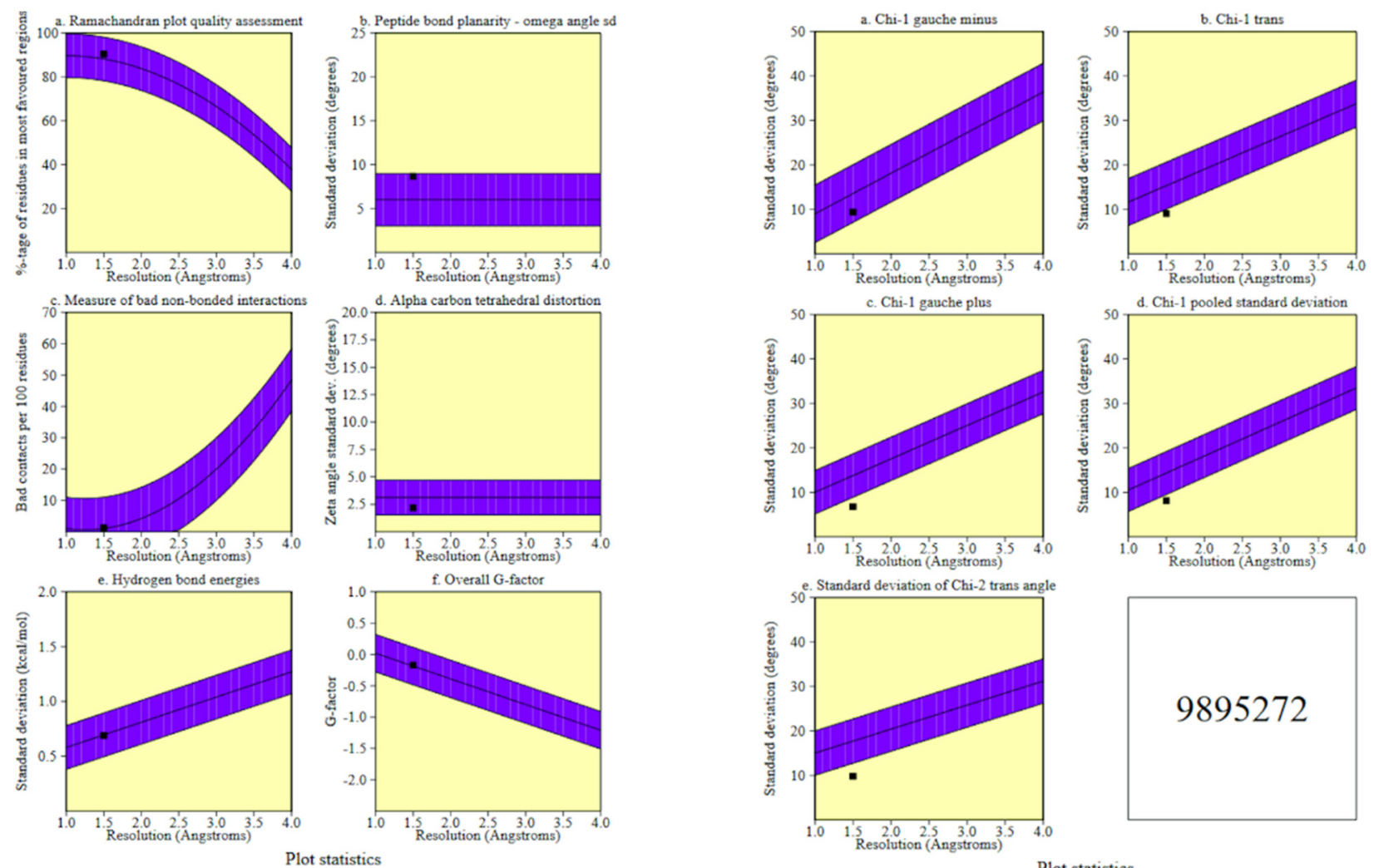

Plot statistics

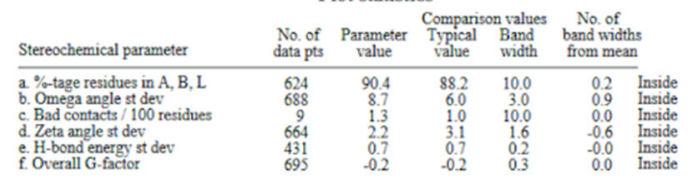

(a)

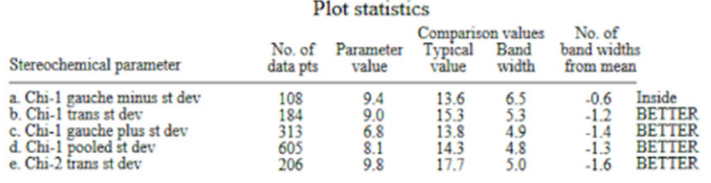

(b)

Figure 3. Main-chain (a) and side-chain parameters (b). 


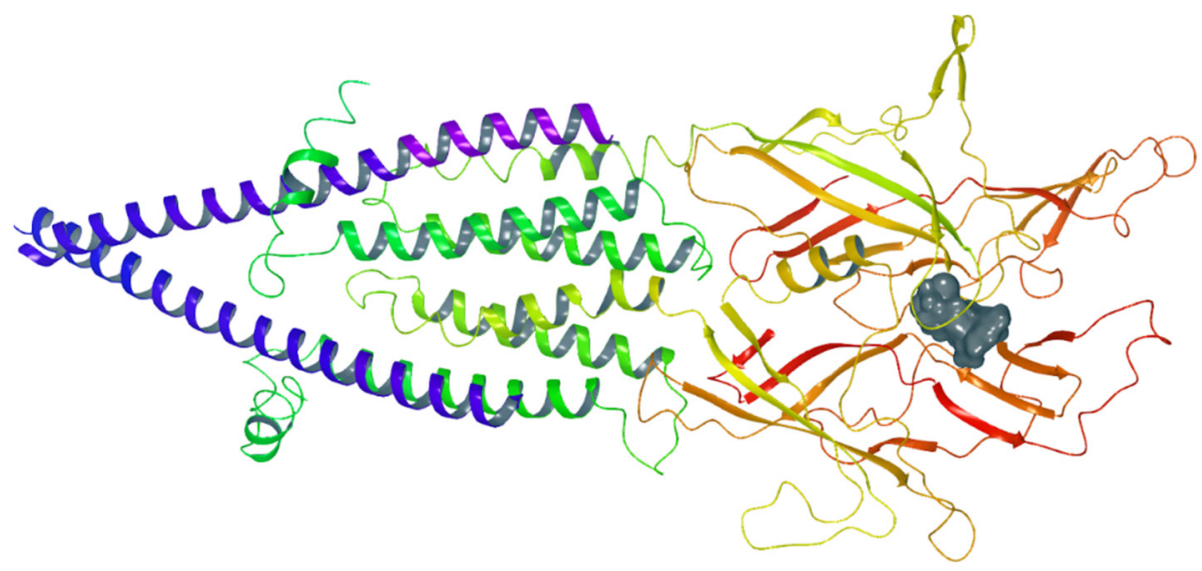

Figure 4. The homology model of the acetylcholine receptor of A. craccivora. The binding site is represented by the gray area.

The visual inspection of the docking outcome for these four top-ranked compounds is presented in Figure 5.

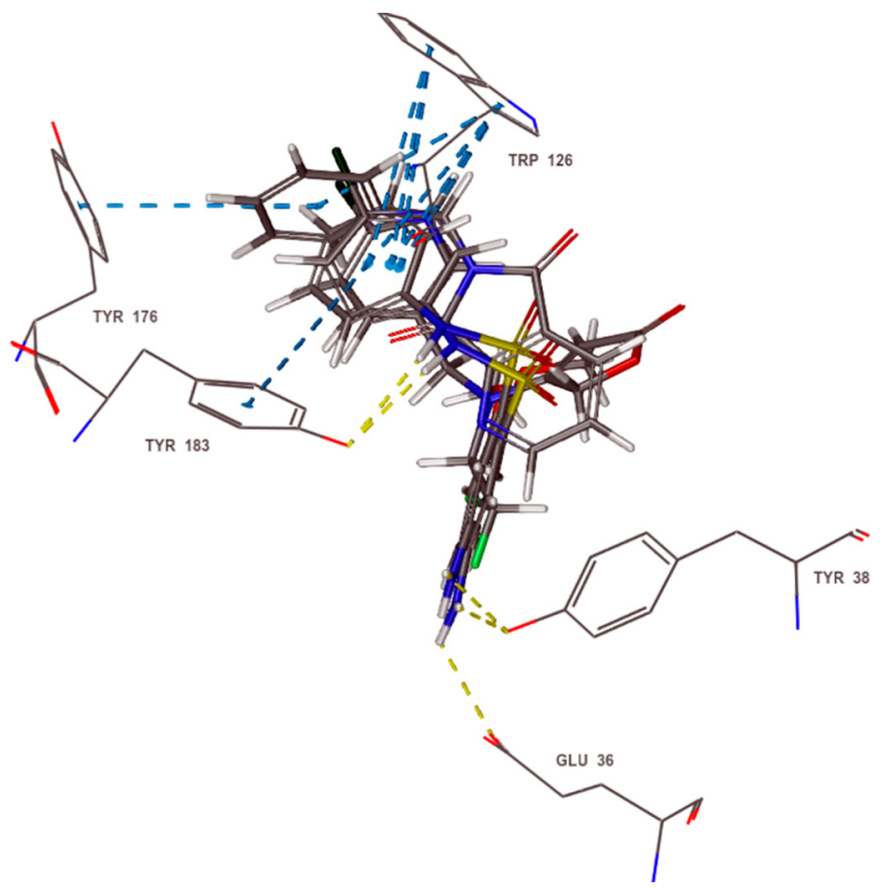

Figure 5. The binding site of the acetylcholine receptor homology model along with the four topranked compounds. The compounds are represented by sticks and the binding site amino acids by lines. The hydrophobic interactions are highlighted by blue dashed lines, while the yellow dashed lines represent the hydrogen bonds.

From the superposition of the compounds in the binding site (Figure 5), it can be observed that the most common is a hydrophobic interaction with the Trp126(A) residue. Our finding is also supported by another study [41], in which the equivalent residue Trp147(A) of the crystal structure of acetylcholine-binding proteins (3C79-PDB ID) has an important hydrophobic interaction with the co-crystallized pesticide imidacloprid. Further, the hydrophobic interactions of the ligands through aromatic rings with the other two amino acid residues (Tyr183(A) and Tyr176(A)) lead to their stabilization in the binding site.

It has been found that Tyr residues play an important role in the acetylcholine-binding protein site [41,42], by forming both hydrophobic interactions and hydrogen bonds 
(Figure 5). As one can see, an amino acid from chain B, namely Glu36, participates additionally as an acceptor in the formation of a hydrogen bond.

\title{
4. Conclusions
}

In order to realize a structure-based virtual screening experiment, a qualitative homology model for the acetylcholine receptor subunit alpha-L1 of Aphis craccivora was built. A dataset of structures retrieved from the literature was docked in the binding site of the receptor. Four top-ranked compounds were further analyzed. Their poses showed important hydrophobic and hydrophilic interactions with the residues, which were also confirmed by other studies as being key amino acids in the acetylcholine receptor-neonicotinoid insecticide interactions. Additionally, the toxic character for bees of these compounds was evaluated with the aid of the BeeTox server. They were predicted to be safe and, thus, we can conclude that the compounds proposed by us could be further tested to confirm their potential insecticidal activity against $A$. craccivora.

\begin{abstract}
Author Contributions: Conceptualization, A.B. (Ana Borota) and S.F.T.; methodology, A.B. (Ana Borota), L.C., S.F.T., and A.B. (Alina Bora); investigation, S.F.T, A.B. (Ana Borota), L.C., and A.B. (Alina Bora); writing-original draft preparation, A.B. (Ana Borota); writing-review and editing, S.F.T; supervision, S.F.T. and A.B. (Ana Borota). All authors have read and agreed to the published version of the manuscript.
\end{abstract}

Funding: This research received no external funding.

Institutional Review Board Statement: Not applicable.

Informed Consent Statement: Not applicable.

Data Availability Statement: The datasets generated during and/or analysed during the current study are available from the corresponding author on reasonable request.

Acknowledgments: This work was financially supported by Project No. 1.1/2020 of the "Coriolan Drăgulescu" Institute of Chemistry, Timisoara. Access to the OpenEye Ltd. and BIOVIA, Dassault Systèmes (for the Discovery Studio Visualizer) software is gratefully acknowledged by the authors.

Conflicts of Interest: The authors declare no conflict of interest.

\section{References}

1. CIE. Distribution Maps of Plant Pests, No. 99; CAB International: Wallingford, UK, 1983.

2. Mayeux, A. The groundnut aphid. Biology and control. Oleagineux 1984, 39, 425-434.

3. CABI. Invasive Species Compendium. Available online: https://www.cabi.org/isc/datasheet/6192\#38F61CAB-1521-41AB-9EC98E3C2F494D5B (accessed on 5 November 2020).

4. Dhingra, S. Development of resistance in the bean aphid, Aphis craccivora Koch, to various insecticides used for nearly a quarter century. J. Entomol. Res. 1994, 18, 105-108.

5. European, Food Safety Authority. Conclusion on the peer review of the pesticide risk assessment for bees for the active substance imidacloprid. EFSA J. 2013, 11, 3068.

6. Tomizawa, M.; Casida, J.E. Neonicotinoid Insecticide Toxicology: Mechanisms of Selective Action. Annu. Rev. Pharmacol. Toxicol. 2005, 45, 247-268, doi:10.1146/annurev.pharmtox.45.120403.095930.

7. Muth, F.; Leonard, A.S. A neonicotinoid pesticide impairs foraging, but not learning, in free-flying bumblebees. Sci. Rep. 2019, 9, 1-13, doi:10.1038/s41598-019-39701-5.

8. Wang, F.; Yang, J.-F.; Wang, M.-Y.; Jia, C.-Y.; Shi, X.-X.; Hao, G.-F.; Yang, G.-F. Graph attention convolutional neural network model for chemical poisoning of honey bees' prediction. Sci. Bull. 2020, 65, 1184-1191, doi:10.1016/j.scib.2020.04.006.

9. Waterhouse, A.; Bertoni, M.; Bienert, S.; Studer, G.; Tauriello, G.; Gumienny, R.; Heer, F.T.; de Beer, T.A.P.; Rempfer, C.; Bordoli, L.; et al. SWISS-MODEL: Homology modelling of protein structures and complexes. Nucleic Acids Res. 2018, 46, W296-W303, doi:10.1093/nar/gky427.

10. Studer, G.; Rempfer, C.; Waterhouse, A.M.; Gumienny, G.; Haas, J.; Schwede, T. QMEANDisCo-Distance constraints ap-plied on model quality estimation. Bioinformatics 2020, 36, 1765-1771.

11. Altschul, S.F.; Gish, W.; Miller, W.; Myers, E.W.; Lipman, D.J. Basic local alignment search tool. J. Mol. Biol. 1990, 215, 403-410, doi:10.1016/s0022-2836(05)80360-2.

12. Guex, N.; Peitsch, M.C. SWISS-MODEL and the Swiss-PdbViewer: An environment for comparative protein modeling. Electrophoresis 1997, 18, 2714-2723. 
13. Laskowski, R.A.; MacArthur, M.W.; Moss, D.S.; Thornton, J.M. PROCHECK-A program to check the stereochemical quality of protein structures. J. App. Cryst. 1993, 26, 283-291.

14. Hou, S.; Zhuang, Y.; Deng, Y.; Xu, X. Photostability study of cis-configuration neonicotinoid insecticide cycloxaprid in water. J. Environ. Sci. Health B 2017, 52, 525-537.

15. Zou, M.; Tian, X.; Chen, N.; Shao, X. Nematicidal Activity of Sprio and Bridged Heterocyclic Neonicotinoid Analogues against Meloidogyne incognita. Lett. Drug Des. Discov. 2015, 12, 439-445, doi:10.2174/1570180812666141125003823.

16. Fu, Q.; Zhang, J.; Xu, X.; Wang, H.; Wang, W.; Ye, Q.; Li, Z. Diastereoselective Metabolism of a Novel Cis-Nitromethylene Neonicotinoid Paichongding in Aerobic Soils. Environ. Sci. Technol. 2013, 47, 10389-10396, doi:10.1021/es4023738.

17. Xu, T.; Wang, X.; Zhang, Q.; Fan, J.; Liu, L.; Liu, M.; Zhang, H.; Li, J.; Guo, Y. Iodine-mediated oxidative cyclization for one pot synthesis of new 8-hydroxyquinaldine derivatives containing a N-phenylpyrazole moiety as pesticidal agents. Bioorg. Med. Chem. Lett. 2018, 28, 3376-3380, doi:10.1016/j.bmcl.2018.08.041.

18. Kong, W.; Bao, Y.; Ma, Q.; Xu, H. Synthesis and biological activities of novel pyrazolomatrine derivatives. Bioorg. Med. Chem. Lett. 2018, 28, 3338-3341, doi:10.1016/j.bmcl.2018.09.008.

19. Dai, H.; Chen, J.; Li, G.; Ge, S.; Shi, Y.; Fang, Y.; Ling, Y. Design, synthesis, and bioactivities of novel oxadiazole-substituted pyrazole oximes. Bioorg. Med. Chem. Lett. 2017, 27, 950-953, doi:10.1016/j.bmcl.2016.12.083.

20. Dai, H.; Ge, S.; Guo, J.; Chen, S.; Huang, M.; Yang, J.; Sun, S.; Ling, Y.; Shi, Y. Development of novel bis-pyrazole derivatives as antitumor agents with potent apoptosis induction effects and DNA damage. Eur. J. Med. Chem. 2018, 143, 1066-1076, doi:10.1016/j.ejmech.2017.11.098.

21. Chen, C.; Chen, J.; Gu, H.; Bao, N.; Dai, H. Design, Synthesis, and Biological Activities of Novel Pyrazole Oxime Com-pounds Containing a Substituted Pyridyl Moiety. Molecules 2017, 22, 878.

22. Bavadi, M.; Niknam, K.; Shahraki, O. Novel pyrrole derivatives bearing sulfonamide groups: Synthesis in vitro cytotoxicity evaluation, molecular docking and DFT study. J. Mol. Struct. 2017, 1146, 242-253, doi:10.1016/j.molstruc.2017.06.003.

23. Jeanmart, S.A.M.; Edmunds, A.J.; Lamberth, C.; Pouliot, M. Synthetic approaches to the 2010-2014 new agrochemicals. Bioorg. Med. Chem. 2016, 24, 317-341, doi:10.1016/j.bmc.2015.12.014.

24. Cheng, X.; Wang, Y.; Li, W.; Li, Q.; Luo, P.; Ye, Q. Nonstereoselective foliar absorption and translocation of cycloxaprid, a novel chiral neonicotinoid, in Chinese cabbage. Environ. Pollut. 2019, 252, 1593-1598, doi:10.1016/j.envpol.2019.06.122.

25. Sun, C.-W.; Wang, J.; Wu, Y.; Nan, S.-B.; Zhang, W.-G. Novel Nitenpyram Analogues with Tetrahydropyridone Fixed Cis-Configuration: Synthesis, Insecticidal Activities, and Molecular Docking Studies. Heterocycles 2013, 87, 1865-1880, doi:10.3987/com13-12766.

26. Du, X.X.; Huang, R.; Yang, C.L.; Lin, J. Synthesis and evaluation of the antitumor activity of highly functionalised pyri-din-2ones and pyrimidin-4-ones. RSC Adv. 2017, 7, 40067-40073.

27. Nishiwaki, H.; Kuriyama, M.; Nagaoka, H.; Kato, A.; Akamatsu, M.; Yamauchi, S.; Shuto, Y. Synthesis of imidacloprid derivatives with a chiral alkylated imidazolidine ring and evaluation of their insecticidal activity and affinity to the nicotinic acetylcholine receptor. Bioorg. Med. Chem. 2012, 20, 6305-6312.

28. Jiang, D.; Zheng, X.; Shao, G.; Ling, Z.; Xu, H. Discovery of a Novel Series of Phenyl Pyrazole Inner Salts Based on Fipronil as Potential Dual-Target Insecticides. J. Agric. Food Chem. 2014, 62, 3577-3583, doi:10.1021/jf405512e.

29. Liu, S.-H.; Peng, W.; Qu, Y.-Y.; Xu, D.; Li, H.-Y.; Song, D.-L.; Duan, H.-X.; Yang, X.-L. Synthesis, insecticidal activity and molecular docking study of clothianidin analogues with hydrazide group. Chin. Chem. Lett. 2014, 25, 1017-1020, doi:10.1016/j.cclet.2014.03.026.

30. Hua, X.; Mao, W.; Fan, Z.; Ji, X.; Li, F.; Zong, G.; Song, H.; Li, J.; Zhou, L.; Zhou, L.; et al. Novel Anthranilic Diamide Insecticides: Design, Synthesis, and Insecticidal Evaluation. Aust. J. Chem. 2014, 67, 1491-1503.

31. Shen, H.F.; Chen, X.; Liao, P.; Shao, X.S.; Li, Z.; Xu, X.Y. Design, synthesis, and insecticidal bioactivities evaluation of pyr-roleand dihydropyrrole-fused neonicotinoid analogs containing chlorothiazole ring. Chin. Chem. Lett. 2015, 3245, 1-4.

32. Liu, J.; Li, Y.; Chen, Y.; Hua, X.; Wan, Y.; Wei, W.; Song, H.; Yu, S.; Zhang, X.; Li, Z. Design, Synthesis, Antifungal Activities and SARs of (R)-2-Aryl-4,5-dihydrothiazole-4-carboxylic Acid Derivatives. Chin. J. Chem. 2015, 33, 1269-1275, doi:10.1002/cjoc.201500619.

33. Liu, J.B.; Li, Y.X.; Zhang, X.L.; Hua, X.W.; Wu, C.C.; Wei, W.; Wan, Y.Y.; Cheng, D.D.; Xiong, L.X.; Yang, N.; et al. Novel Anthranilic Diamide Scaffolds Containing N-Substituted Phenylpyrazole as Potential Ryanodine Receptor Activators. J. Agric. Food Chem. 2016, 64, 3697-3704.

34. He, Y.; Hu, D.; Lv, M.; Jin, L.; Wu, J.; Zeng, S.; Yang, S.; Song, B. Synthesis, insecticidal, and antibacterial activities of novel neonicotinoid analogs with dihydropyridine. Chem. Cent.J. 2013, 7, 1-6, doi:10.1186/1752-153x-7-76.

35. OMEGA. OMEGA 4.0.0.4: OpenEye Scientific Software; OMEGA: Santa Fe, NM, USA, 2019.

36. Hawkins, P.C.D.; Skillman, A.G.; Warren, G.L.; Ellingson, B.A. StahlMT Conformer generation with OMEGA: Algorithm and validation using high quality structures from the protein databank and Cambridge structural database. J. Chem. Inf. Model. 2010, $50,572-584$.

37. FRED. FRED 3.5.0.4: OpenEye Scientific Software; FRED: Santa Fe, NM, USA, 2020.

38. McGann, M. FRED Pose Prediction and Virtual Screening Accuracy. J. Chem. Inf. Model. 2011, 51, 578-596, doi:10.1021/ci100436p.

39. McGann, M. FRED and HYBRID docking performance on standardized datasets. J. Comput. Mol. Des. 2012, 26, 897-906, doi:10.1007/s10822-012-9584-8.

40. BIOVIA. Dassault Systèmes, [Discovery Studio Visualizer]; v20.1.0.19295; Dassault Systèmes: San Diego, CA, USA, 2019. 
41. Talley, T.T.; Harel, M.; Hibbs, R.E.; Radic, Z.; Tomizawa, M.; Casida, J.E.; Taylor, P. Atomic interactions of neonicotinoid agonists with AChBP: Molecular recognition of the distinctive electronegative pharmacophore. Proc. Natl. Acad. Sci. USA 2008, 105, 7606-7611, doi:10.1073/pnas.0802197105.

42. Ihara, M.; Okajima, T.; Yamashita, A.; Oda, T.; Hirata, K.; Nishiwaki, H.; Morimoto, T.; Akamatsu, M.; Ashikawa, Y.; Kuroda, S.; et al. Crystal structures of Lymnaea stagnalis AChBP in complex with neonicotinoid insecticides imidacloprid and clothianidin. Invert. Neurosci. 2008, 8, 71-81. 